Chapman University

Chapman University Digital Commons

ESI Publications

Economic Science Institute

2015

\title{
Risky Business: An Analysis Of Teacher Risk Preferences
}

Daniel H. Bowen

University of Arkansas

Stuart Buck

University of Arkansas

Cary Deck

Chapman University, deck@chapman.edu

Jonathan N. Mills

University of Arkansas

James V. Shuls

University of Arkansas

Follow this and additional works at: http://digitalcommons.chapman.edu/esi_pubs

Part of the Economic Theory Commons, and the Other Economics Commons

\section{Recommended Citation}

Bowen, D., Buck, S., Deck, C., Mills, J., and Shuls J. (2015). "Risky Business: an Analysis of Teacher Risk Preferences," Education Economics 23(4), 470-480. DOI: 10.1080/09645292.2014.966062

This Article is brought to you for free and open access by the Economic Science Institute at Chapman University Digital Commons. It has been accepted for inclusion in ESI Publications by an authorized administrator of Chapman University Digital Commons. For more information, please contactlaughtin@chapman.edu. 


\section{Risky Business: An Analysis Of Teacher Risk Preferences}

\section{Comments}

This is an Accepted Manuscript of an article published in Education Economics in 2015, available online: DOI: $10.1080 / 09645292.2014 .966062$

\section{Copyright}

Taylor \& Francis 


\title{
Risky Business: An Analysis of Teacher Risk Preferences
}

\author{
Daniel H. Bowen* \\ University of Arkansas \\ Stuart Buck \\ University of Arkansas \\ Cary Deck \\ University of Arkansas \\ Jonathan N. Mills \\ University of Arkansas \\ James V. Shuls \\ University of Arkansas
}

EDRE Working Paper No. 2013-01

Last Updated March 2013

Please Do Not Cite without Author Permission

\begin{abstract}
Teachers often oppose policy reforms aimed at improving teacher effectiveness. One potential explanation for their objections is that teachers, as a group, are relatively risk averse. This paper addresses this explanation through the use of a risk preference elicitation task common in experimental economics. Comparing the risk preferences of future teachers with those entering other professions, we find that individuals selecting into teaching careers are significantly more risk averse. At the same time, we do not find evidence that compensation format preferences alone are responsible for attracting more risk-averse individuals into teaching, as risk aversion does not appear to correlate with a stated preference for step and lane pay. Policymakers should take into account teacher risk characteristics when considering policy changes that may clash with teacher preferences.
\end{abstract}

*Corresponding author: Address: 208 Graduate Education Building, University of Arkansas, Fayetteville, AR, 72701; Tel.: +1 479575 6345; Email: dhbowen@email.uark.edu 


\section{Introduction}

Research has demonstrated that an effective teacher can significantly increase how much students learn in the classroom (Chetty, Friedman, \& Rockoff, 2011; Hanushek, 1992). In fact, the difference between an effective and ineffective teacher could be as much as an extra year of learning for students (Hanushek, 2002). However, while most private sector workers paid based upon their performance, most American teacher salaries are determined by a single salary schedule, often referred to as a "step and lane" pay scale. First introduced in 1921, by 1950 roughly $97 \%$ of all schools in the United States adopted a step and lane pay schedule (Prostik, 1996). Currently, the vast majority of K-12 teachers in a school district start at the same base salary regardless of teaching subject or grade level. Rather than reward teachers for performance, step and lane pay schedules offer salary increases for each year of service and for additional coursework, typically college credit hours or advanced degrees. Therefore, under this pay scheme, a highly effective teacher and a highly ineffective teacher who begin teaching in the same school at the same time will earn the exact same salary.

While step and lane salary schedules have been the norm in public education for nearly six decades, there has been a push to reform teacher pay recently. Secretary of Education Arne Duncan and President Obama have publicly supported the development of merit pay systems for teachers. The Department of Education has established a grant program, the Teacher Incentive Fund, that supports the development of performance-based compensation systems. Paying teachers based on their performances has also grown in popularity with the general public. In a recent public opinion poll, $47 \%$ of those surveyed favor "paying teachers, in part, based on the academic progress of their students on state tests," while only $27 \%$ were opposed to merit pay 
(Howell, West, \& Peterson, 2011, p. 14). However, the same poll finds that $72 \%$ of teachers oppose performance-based pay.

There are many reasons why teachers might oppose such incentive schemes. A step and lane scale may contribute to a steady workforce by encouraging individuals to remain in the profession throughout their career. A stable pay scale might also enable teachers to experiment with new and potentially improved teaching techniques that they might not try otherwise. Teachers might fear that merit pay could bring about a more acute focus on a narrow academic element of schooling to the detriment of other valuable areas (Wilms \& Chapleau, 1999). Teachers may also worry about the reliability of tests to accurately measure student performance (Koedel, 2009). Additionally, teachers may fear that rewarding individual performance may reduce the incentives for teachers to collaborate with one another and could even create conflict (Ritter \& Jensen, 2010).

Another plausible, yet relatively unexplored, explanation for teacher opposition is that individuals who go into teaching may be relatively more risk averse than the general population. Studies in a variety of fields have noted that compensation schemes impact workforce composition (Dohmen \& Falk, 2011; Lazear, 2000). Relative to private sector employees, teachers receive lower average pay but have less pay variability and more generous health benefits, pensions, and job security (Podgursky, 2003). These features of the compensation system could entice relatively risk-averse individuals into the profession. If teachers are in fact more risk averse than other workers, teacher opposition to performance pay systems is unsurprising.

In this paper, we explore teachers' risk preferences using a lottery-based risk elicitation tool common to the experimental economics literature. Using responses on this task, we compare 
the risk attitudes of future teachers with the risk preferences of students in master of business administration (MBA) and juris doctorate (JD) programs. By focusing on graduate students preparing to enter teaching and other professional careers, we can focus on the issue of selfselection into low risk careers while eliminating any effect experience in teaching might have on behavior. We also survey participants on key demographic information, as well as their likelihoods of going into teaching, and their preferences for four different types of pay systems.

\section{Literature Review}

Public sector jobs often come with tenure or civil service protections that are far more protective than the employment-at-will relationships pervasive in the private sector.

Unsurprisingly, economists have long found that public sector workers tend to be more risk averse than private sector workers (e.g. Dohmen et al., 2005; Hartog, Ferrer-i-Carbonell, \& Jonker, 2002; Masclet, Colombier, Denant-Boemont, \& Loheac, 2009). Bellante and Link (1981) find that risk aversion, measured from survey responses, is a significant predictor of public sector employment. Buurman, Delfgaauw, Dur, and Van den Bossche (2012) find that public sector workers' odds of choosing a riskier reward for filling out a survey are only slightly more than half of that of a private sector worker.

As for the risk aversion of teachers in particular, much of the previous work is anecdotal (e.g. Wagner, 2001) or is based on survey data lacking salient rewards (e.g. Davis, 1994). One exception is Perez (2011) who compares the risk preferences, attitudes towards pay inequity, and preferences toward competition of female teacher candidates to female law students. In the study, subjects were asked to complete a series of 10-minute rounds of solving mazes with different pay schemes. In the final round, some participants were asked individually what pay scheme they would prefer, while the others were asked to make decisions that would apply to the 
rest of the group. Perez finds that teachers do not exhibit higher levels of risk aversion than the lawyers; however teachers were significantly more likely to be averse to pay inequity. Perez claims that this finding suggests that teachers have fundamental inclinations towards greater pay equity and that policymakers should take this inclination into consideration.

While our study is closely related to Perez's, it differs in a few ways. First, we include males in our sample. Even though the majority of teachers are women, we want to try and determine whether the risk preferences of individuals who choose to teach are independent of gender. Second, we use individuals' choices with regard to different lotteries in order to elicit risk preferences. Finally, we examine whether there is a significant relationship between individuals' risk preferences and their preferences for different forms of compensation.

Thus, while research demonstrates that public sector employees tend to be more risk averse than private sector workers, relatively few studies have examined teacher risk preferences in a controlled setting. This paper addresses this gap in the research using a risk preference elicitation tool commonly used in experimental economics. In the next section, we introduce the instrument and outline our experimental procedure.

\section{Methods}

\subsection{Risk Elicitation Task}

To measure the risk attitudes of future teachers relative to the participants in the MBA and JD programs, we use the Holt and Laury (2002) risk preference task. This tool is a wellknown, commonly used risk-elicitation procedure in the experimental economics literature (e.g. Anderson, Harrison, Lau, \& Rutstrom, 2008; Dohmen, Falk, Huffman, \& Sunde, 2010; Eckel \& Wilson, 2004). While there are alternative controlled procedures for measuring risk, this procedure has become a generally accepted standard. In part this is due to the ease with which it can be implemented and explained to subjects. Further, Harrison, Johnson, McInnes, and 
Rutstrom (2005) have found this procedure to have high retest reliability over an extended time frame.

The procedure, shown in Table 1 as it was presented to participants, estimates risk preferences by examining subject choices between lotteries with different real dollar payouts. In particular, subjects are asked to choose between two options (A and B) for each of 10 lotteries with the understanding that they will receive the outcome from one particular lottery chosen at random. The possible payouts are held fixed for each option, with Option A payoffs ( $\$ 4.80$ or $\$ 6.00)$ having less variability than Option B payoffs ( $\$ 0.30$ or $\$ 11.55)$. The chance of receiving the higher of the two payouts for either option increases by 10 percentage points with each lottery. In Lottery 10, a participant is guaranteed to receive the larger payoff amount from the selected option and thus should strictly prefer the $\$ 11.55$ from Option B to the $\$ 6.00$ from Option A.

Risk preferences are modeled using a constant relative risk aversion functional form of utility, $u(x)=x^{1-r}$, where individual utility is a function of payout $x$ and their risk preference parameter $r$. In this framework, individuals are classed into one of three groups based on the value of $r$ : risk averse $(r>0)$, risk neutral $(r=0)$, and risk preferring $(r<0)$. Individuals with $r=0$ are considered risk neutral because their utility is solely determined by their expected payout. In contrast, individuals with $r>0$ are risk averse as their utility down-weights the expected payout because $(1-r)<1$ when $r>0$. Finally, $r<0$ is associated with risk loving preferences as such individuals prefer increased uncertainty.

The switching point from Option A to Option B identifies a range of risk parameters that are consistent with the observed choice (see Holt \& Laury, 2002). It is conceivable that an extremely risk-loving individual would select Option B for every choice, but monotonicity is 
sufficient to cause people to select Option B for choice 10 where one is assured of receiving the higher payoff. A risk-neutral individual is concerned with the expected payouts from the two options in a given lottery and will choose Option A for the first four lotteries and Option B for the remaining lotteries. Risk-averse individuals are willing to forgo expected value in exchange for reduced uncertainty and therefore will continue choosing Option A even after the fourth lottery despite the higher expected payout from Option B. Risk-loving individuals will make the switch to Option B before the fifth lottery despite the higher expected payout from Option A.

The Holt and Laury (2002) procedure not only provides rich information on individual preferences, it also allows us to check the extent to which subject confusion exists in our data: individuals should never select Option A on Lottery X after having selected Option B for Lottery $\mathrm{Y}$ if $\mathrm{X}>\mathrm{Y}$. Therefore multiple switches serve as one indicator of participant confusion.

\subsection{Experimental Procedure}

A total of 132 subjects completed the study, all of whom were graduate students at a major, public university in the southeast region of the United States. Our group of interest consisted of 65 prospective teachers recruited from the university's Master's in the Art of Teaching (MAT) Program. Of these, 32\% were studying to teach at the elementary level while $68 \%$ were studying to teach at the middle or secondary level. The students spend an academic year taking coursework while student teaching at traditional public schools. Upon completion of the program, students become certified teachers in the state. We chose MAT students, as opposed to undergraduates with declared education majors, because of greater certainty that these students will ultimately end up teaching in the near future. In fact, according to a conservative estimate from the MAT program coordinator, more than $90 \%$ of the MAT students take on a teaching position in the academic year immediately after completing the program. 
Additionally, the MAT program is the only route a student at this particular university can take to earn a traditional teaching license. Future elementary teachers can earn a bachelor's degree in education, while middle and secondary teachers typically first earn a bachelor's degree in their content areas. Therefore, while education undergraduates are almost entirely elementary education majors, MAT students represent a more even distribution of elementary, middle, and high school teachers.

The comparison group for this study is composed of graduate students in other fields. In particular, future teachers are compared to 43 students in the university's MBA program in addition to 24 JD students. We chose these students to serve as a comparison group because they are similarly pursuing graduate professional degrees.

To conduct the study, we obtained permission from university faculty to offer their students the opportunity to participate in a paid research study on economic decision making. The experiments were conducted during the last fifteen minutes of class. Instructors were asked to leave the room prior to the study and participants were aware that their responses would be kept anonymous. The students were not made aware of the opportunity to participate in the study prior to our arrival. After the instructor left, we briefly described the experiment and reviewed the participation consent form that subjects would be required to sign in order to receive payment. Students were free to leave at any point as participation was voluntary. ${ }^{1}$ Participants were then given a single, two-sided sheet of paper with instructions for the experiment. This document contained a sample question to verify if the participant understood the experiment, the risk preference elicitation instrument, and a survey of compensation preferences as well as demographic questions (see Appendix). Participants were told to read the directions, complete a comprehension question, and then raise their hands so that one of the

\footnotetext{
${ }^{1}$ Only two potential subjects opted not to participate; one male and one female in the JD program.
} 
monitors could verify that the subject understood how the elicitation procedure worked before the task was completed. If the subject had completed the sample question correctly, the monitor discreetly marked the form in a particular location on the paper. If the subject had answered incorrectly and needed additional explanation, the monitor discreetly marked the form in a different location. This process allowed us to track which subjects experienced at least some initial confusion about the task.

After an experimenter checked the comprehension question and verified that the participant understood the instructions, the participant was asked to complete the risk elicitation task and complete the brief survey. The risk elicitation procedure was on the front of the response form and the survey was on the other side (see Appendix). Participants were aware the survey existed when completing the risk elicitation tool, but did not know the contents of the survey. The survey was completed after the lottery in order to avoid the possibility that these questions could frame or influence subjects' behaviors while listing their lottery preferences.

The first half of the survey asked participants about their preferences for four different pay system scenarios. We used the same scenarios that Milanowski (2007) used to survey students who were preparing to become teachers. We asked participants, on a scale of -4 (highly undesirable) to +4 (highly desirable), to indicate how desirable or undesirable they would find each particular pay format for their first chosen occupation. The four formats were pay for individual performance, pay for the development of knowledge and skills, pay for team performance, and pay not based on performance.

The last part of the survey included questions about background information to control for other potentially salient characteristics. Specifically, we collected individual age, gender, proxies for income level, and mother's level of education, as well as the individual's estimated 
likelihood that they would ever enter the teaching force. ${ }^{2}$ Our proxies for wealth include the make and model of a participant's car and how many times they eat at a restaurant in a given week. We used these proxies rather than asking for current income level, both to elicit honest answers and to account for the possibility of inaccurate reports of graduate student incomes. Upon completion of the study, participants brought their response forms to the front of the room. Monitors verified that subjects had completed all of the questions and then rolled a ten-sided die to determine which lottery choice would be used to determine the subject's payment. ${ }^{3}$ Next, the ten-sided die was rolled again to determine the actual payment according to the subject's choice of option A or B for the randomly chosen lottery. On average, participants in the experiment received a payment of $\$ 7.00$. After subjects received their payments, they were dismissed from the study and exited the room. There was no identifying link between the payment record and the participants' response forms in order to preserve their anonymity.

\section{Results}

In this section we present both the risk task and survey results. Before examining differences in behavior between prospective teachers and other students, we compare the composition of the two groups. To make sure that the two groups accurately distinguish individuals who are most likely to teach from those who will not, we asked how likely the participants were to teach in a K-12 setting. More than $97 \%$ of MAT students indicated there was greater than a $75 \%$ chance they would enter teaching, with $60 \%$ stating the likelihood was $100 \%$. In comparison, only $3 \%$ of non-MAT students indicated there was greater than a $75 \%$ chance that they would teach, while more than $89 \%$ indicated there was less than a $25 \%$ chance. These

\footnotetext{
2 The latter variable was collected to verify that one's degree program was a reliable proxy of career intentions.

${ }^{3}$ Randomly selecting one task for payment is a common approach in experiments where the researcher wants to control for potential wealth effects (see e.g. Holt \& Laury, 2002).
} 
responses give us confidence that the participants in our experiment accurately captured future teachers and individuals not likely to teach in a K-12 setting.

Table 2 provides summary demographic information for the MAT and non-MAT samples. The overall sample consists of more females, but males represent a majority among non-MAT students. White participants represent the overwhelming majority in the MAT sample, while the non-MAT sample is more diverse. In addition to simple demographics, we examined the extent to which the MAT and non-MAT samples varied on wealth proxies. In general, the two samples did not significantly differ on level of mother's education, number of days they ate out in a given week, or with the Blue Book value of their personal vehicles.

Our experimental procedures provided us with two opportunities to ascertain individual confusion with the risk elicitation tool. First, after having participants read through the instructions, we had them answer a question on a hypothetical payout. The second test of comprehension is whether the individual made consistent responses (i.e. as opposed to making multiple switches between Lotteries A and B). In Table 3, we present the percentages of correct answers to the comprehension question and percentages of students with consistent responses on the risk elicitation tool. When comparing the overall percentages of confusion in the MAT and non-MAT groups, we find no statistically significant difference between the groups.

Below we present the results of our study in terms of risk preferences and pay preferences. These results include all individuals from our study; we do not limit our analyses to only those participants who lacked any difficulty comprehending the risk task. This allows us to utilize our full data set. We have also conducted the same analyses excluding individuals that 
exhibited confusion. While point estimates differ between the two sets of analyses, estimate signs and significance generally remain unchanged. ${ }^{4}$

\subsection{Risk Preference}

In Table 4, we present a comparison of the average number of times an individual went with the "safer" (i.e. lower payout variance) choice, Option A. On average, participants made 4.7 safe choices. MAT students, on average, made 5 safe choices while non-MAT students made 4.3. Figure 1 presents the distribution of the proportion of individuals making safe choices in each lottery for MAT and non-MAT students. The dotted line serves as a reference, indicating how a perfectly risk-neutral group would respond to the risk-elicitation tool. Consistent with the comparison of averages in Table 4, Figure 1 indicates non-MAT students are more willing to take risks. For example, in lottery 5 (where a risk-neutral individual would first make a switch away from the safer choice), $39 \%$ of non-MAT, as opposed to $60 \%$ of MAT students, chose the safer option. The greater willingness of non-MAT students to take risks is supported by a Kolmogorov-Smirnov test that compares these two distributions ( $\mathrm{p}$-value $<0.01$ ). The central tendencies of the two distributions also differ based upon a Mann-Whitney test (p-value < 0.01).

Since our sample of future teachers is mostly female while the non-MAT group is mostly male, a gender effect may be driving our main result. Figure 2 presents a comparison of outcomes for females and males. The strong similarities between the male and female distributions suggest a lack of a gender effect. The Mann-Whitney and Kolmogorov-Smirnov tests both support this conclusion as they fail to find a significant gender effect ( $\mathrm{p}$-values $=0.79$

\footnotetext{
${ }^{4}$ The only changes in significance that take place are in 2 of the 12 analyses. The coefficient for MAT is always positive and statistically significant at conventional levels in 10 of these 12 analyses and always for models 1,2 , and 3. However, when removing participants that did not initially get the initial item check correct, the coefficient on MAT is $0.90(\mathrm{p}=0.11)$ in the $4^{\text {th }}$ model when controlling for the number of times that a participant eats out in a given week (wealth proxy 2). When removing any participants that demonstrated confusion in terms of switching options more than once, the coefficient on MAT is $0.91(\mathrm{p}=0.12)$ in the $3^{\text {rd }}$ model when controlling for the number of times that a participant eats out in a given week.
} 
and 0.67 , respectively). This finding may seem counterintuitive as prior research has found women to be more risk averse than men (e.g. Eckel \& Grossman, 2008; Schubert, Gysler, Brown, \& Brachinger, 1999). Nevertheless, there are experimental studies that have found no significant gender differences in risk behavior (e.g. Harbaugh, Krause, \& Vesterlund, 2002; Moore \& Eckel, 2003). The lack of gender effect in our study is likely due to the highly risk averse MAT males increasing the overall average number of male safe choices.

We also examine results of gender differences within degree program in Figure 3. While non-MAT males do not appear to strongly differ from non-MAT females, there appears to be a gap between MAT males and females, with males significantly choosing the safer choice more often on average. Among males in the MAT program, $63 \%$ made 6 safe choices or more indicating a high degree of risk aversion. Mann-Whitney and Kolmogorov-Smirnov tests reject the null hypothesis of similar distributions between male MAT and both female MAT and male non-MAT participants (see Table 5).

In addition to comparing the number of safe choices by each group, we conduct regression analyses to examine the risk attitudes between those in the two degree programs while controlling for other demographic variables. Table 6 reports the results of four different specifications where the dependent variable is the number of safe choices. The first specification examines only the relationship between degree program and risk aversion. While the second through fourth specifications include additional covariates such as gender, race, age, income, and confusion, MAT program enrollment is the only variable that predicts risk attitude. In the first specification, MAT program enrollment is associated with participants choosing an average of 0.70 more safe choices (Option A). This result holds when we additionally control for gender in 
the second specification: MAT program enrollment is associated with significantly more safe choices; however gender has no significant impact on the number of safe choices.

In the third specification, we include gender interacted with the MAT program as well as indicators for race, age, and whether a subject experienced confusion in interpreting the lottery task. Males in the MAT program make 1.03 more safe choices than non-MAT males $(\mathrm{p}=0.05)$. Additionally, we compare female MAT and non-MAT student risk preferences by examining the statistical significance of the sum of the MAT and Female*MAT coefficients. A joint F-test rejects the hypothesis that these coefficients sum to zero $(p=0.08)$. Finally, we can examine if there is a gender difference in the number of safe choices among MAT students by testing the statistical significance of the sum of the Female and Female*MAT coefficients. A joint F-test fails to reject the hypothesis that these coefficients sum to zero $(\mathrm{p}=0.57)$. Thus, MAT status is significantly related to making more safe choices when examining different subgroups and controlling for demographics. While MAT males still appear to be the most risk averse subgroup, they are not significantly more risk averse than MAT females.

In the fourth specification, we include a host of variables that attempt to control for student wealth. In particular, we include three wealth proxies: the log of participant car Blue Book values; the number of times the participant reports to eat at a restaurant in a given week; and reported level of mother's education. We ran this analysis with each of these proxies for wealth separately as these measures are likely highly correlated. The findings from the other model specifications remain unchanged. Specifically, we find no significant differences in risk preferences based on an individual's wealth as measured by our proxies. The coefficients for MAT, gender, age, etc. marginally change. However, each coefficient does not change with regard to direction or significance. 
In summary, the results from our analyses of individual risk-preferences indicate that future teachers in our sample are significantly more risk averse than other graduate students. This result holds when we disaggregate by gender: both male and female MAT students are significantly more risk averse than respective non-MAT counterparts. At the same time, we do not find significant differences in risk preferences among male and female MAT students. These general results hold when we control for additional individual demographics. In the next section, we examine the extent to which these estimated differences in risk preferences correspond to differences in preferences for performance-based compensation schemes.

\subsection{Pay Preferences}

Table 7 describes the average ratings given to each pay system, broken out by group and gender. Overall, there was relatively strong support for individual merit pay based on objective performance as well as based on one's development of knowledge and skills. MAT students were less supportive of team-based pay; these differences are substantial and significant (K-S pvalue $=0.03 ; \mathrm{M}-\mathrm{W}$ p-value $<0.01)$. We also have dichotomized participants' preferences in order to examine the percentage within each group who generally support the different types of pay systems. Once again, MAT students are found to be significantly less likely to support pay for team performance. MAT students are also less likely to support pay for individual performance and pay for developing their knowledge and skills, and they are more likely to support pay raises that are not based on performance. However, these differences are not statistically significant. Finally, there is little to no correlation between individuals' risk and pay system preferences.

The strong overall support for individual merit pay might seem anomalous, especially in the case of risk-averse individuals. This might be because our survey question described 
individual merit pay as the potential to earn a pay increase (i.e. a bonus). It is plausible then that even risk-averse individuals would be supportive of the chance to earn a pay raise when there is no risk of wage loss. Moreover, the prospect of pay for performance for a novice teacher is possibly not perceived as being all that risky. In the following section we summarize our findings and discuss their implications.

\section{Discussion}

We conduct an experiment that allows us to ascertain relative risk preferences for individuals in a MAT program and a comparison group comprising MBA and law students. Our results show clear evidence that those who opt to pursue teaching careers are more risk averse than those pursuing careers in business or law. However, based on the survey responses of our participants, it does not appear as though an early preference for step and lane pay (or an aversion to performance-based pay) systems can independently explain why more risk-averse individuals choose to go into teaching.

Support for the notion that teachers tend to be risk averse could have important implications for education policymakers. Buurman et al. (2012) note that if public employees are more risk averse, "pay-for-performance is a more costly instrument to induce effort in the public sector than in the private sector" (p.4). Similarly, implementing performance pay may increase the levels of tension and worker dissatisfaction (Dohmen \& Falk, 2010; Perez, 2011). Specifically, this disapproval could be attributed to the possibility that the profession has attracted individuals who are relatively risk averse.

In our sample, both future teachers and the comparison group preferred merit pay systems more than they preferred a uniform raise system which is commonly used in education. It is plausible then that even risk-averse individuals would be supportive of the chance to earn a pay 
raise when there is no risk of wage loss. There are at least a couple of reasons why this might be the case for the participants of this study. First, if these future teachers are comparing their possible wages under a performance-based pay system to what they will receive under the step and lane system, then the former system possibly looks more appealing. Early career teachers have the lowest wages in a step and lane pay system and may therefore be more likely to prefer performance-based pay because it offers the chance of making higher wages with relatively low risk. Milanowski’s (2007) research supports this explanation, finding that support for merit pay appears to differ between less experienced and veteran teachers.

Alternatively, future teachers may overestimate their abilities to be high performers. In other words, without evidence to the contrary, these MAT students may not find performancebased pay to be all that risky if they see themselves as being highly effective teachers. Finally, the result may simply be driven by the wording of the survey question, as participants may prefer performance pay when it takes the form of a bonus (i.e. no risk of loss).

There was a significant difference in preference for team-based merit pay plans, with non-MAT students preferring this system more than MAT students. We have no firm hypothesis for why this might be the case, but we speculate that it could be tied to the nature of their prospective professions. The MAT students' opposition to team performance pay could reflect how these future teachers assess their abilities relative to other teachers. In other words, if these future teachers believe that they will be better than average, they may view team performance pay as undesirable (at least relative to their expected earnings under an individual performance pay program). Another possibility is that MBA and law students might be more likely work together on a single project or case. In which case, rewarding workers for the success of the team may closely align with the type of work these future employees aspire to do upon entering the 
workforce. Teachers, on the other hand, have a classroom full of students and may have little influence over how other teachers handle their classes.

\section{Limitations}

Our sample size in addition to using a laboratory environment limits the extent to which we can make broader, more generalizable claims about all teachers' risk characteristics. Moreover, our sample is restricted to prospective teachers coming from one university. Despite these limitations, we hope that our findings build upon as well as facilitate the research on teacher characteristics. We believe that incorporating behavioral measures into this body of research can help increase our knowledge about the types of individuals who are attracted to the teaching profession in addition to a better understanding of the specific aspects of the profession that have fostered this attraction. We do not believe that our findings provide any specific policy prescriptions. Nevertheless, this research can help inform and caution policymakers going forward as they consider ways to attract and retain high quality teachers in addition to positively influencing the performances of those currently in the workforce.

\section{Conclusions}

Our findings provide suggestive evidence that future teachers are indeed more risk averse than individuals in other professions. At the same time, our survey data do not indicate uniform salary schedules or even an aversion to performance-based pay is solely responsible for attracting these relatively risk-averse individuals to the teaching profession. It could be the case that other aspects of teaching are attracting risk-averse individuals to the profession. Another possibility is that these future teachers do not view their participations in performance-based pay programs as very risky. These views could be due to the fact that incoming teachers have relatively little to lose in a step and pay system. It could also be the case that these future 
teachers have a high estimate of their likely effectiveness in the classroom and therefore see little risk in compensation based on their abilities.

Although there are many other issues that need to be taken into consideration in terms of how these results can shape and influence education policy, this evidence can at least inform policy discussions on teacher quality in at least a couple of different ways. For example, our results may suggest that policymakers need to take into greater account teachers' risk preferences when designing performance incentives (e.g. performance pay programs). Moreover, these findings may suggest that the efficacy of policies could depend more on facilitating systemic changes that attract a different pool of individuals into the profession. However, while implementing certain reforms could entice less risk-averse individuals into the teaching profession, the impact that this systemic shift would have on student achievement is unknown.

Future research could compare prospective teachers' preferences, characteristics, and attitudes to more veteran teachers. Perhaps there is a selection effect over time: people who especially like certain aspects of the job might stay in the teaching profession, and those who do not care for these aspects eventually leave the profession. In addition, people who teach for several years might dislike certain characteristics of the job initially, but they might grow to prefer these characteristics over time because of social conformity or because it is a system that fundamentally advantages them as they transition to veteran status.

With regard to systemic changes, future analyses could further explore the nature of personnel changes that might occur with the implementation of certain reforms (e.g. examining whether performance-based pay or the removal of tenure attracts less risk-averse teacher candidates) and assessing if these changes benefit student outcomes. These questions, as well as the ones addressed in this research, will hopefully better inform policymakers on important 
considerations when it comes to implementing changes that potentially alter the nature of the teaching profession and, subsequently, the composition of the teacher workforce.

\section{Acknowledgements}

We thank the panel participants at the 2012 Annual Conference of the Association for Education Finance and Policy for their helpful comments and discussions. We are also grateful to Gary Ferrier, Moez Limayem, and Gary Ritter for providing us with the funding necessary to conduct this research. We also appreciate the assistance and access that Jennifer Beasley, Freddie Bowles, Joshua Foster, Christian Goering, Anna Jacob, Michael McShane, Caleb Rose, and James Woodworth provided throughout the data collection process. 


\section{References}

Anderson, S., Harrison, G. W., Lau, M. I., \& Rutstrom, E. E. (2008). Eliciting risk and time preferences. Econometrica, 76(3), 583-618.

Bellante, D. \& Link, A.N. (1981). Are public sector workers more risk averse than private sector workers? Industrial and Labor Relations Review, 34(3), 408-12.

Buurman, M., Delfgaauw, J., Dur, R., \& Van den Bossche, S. (2012). Public sector employees: Risk averse and altruistic? Journal of Economic Behavior \& Organization 83(3), 279291.

Chetty, R., Friedman, J.N., \& Rockoff, J.E. (2011). The long-term impacts of teachers: Teacher value-added and student outcomes in adulthood (No. w17699). National Bureau of Economic Research.

Davis, J.B. 1994. A closer look at those who have decided to teach. High School Journal, 77 (4), 274-79.

Dohmen, T. \& Falk, A. (2010). You get what you pay for: Incentives and selection in the education system. The Economic Journal, 120(546), F256-F271.

Dohmen, T., \& Falk, A. (2011). Performance pay and multidimensional sorting: Productivity, preferences, and gender. The American Economic Review, 101(2), 556-590.

Dohmen, T., Falk, A., Huffman, D., and Sunde, U. (2010). Are risk aversion and impatience related to cognitive ability? American Economic Review, 100(3), 1238-1260. 
Dohmen, T., Falk, A., Huffman, D., Sunde, U., Schupp, J. \& Wagner, G.G. (2005). Individual risk attitudes: New evidence from a large, representative, experimentally-validated survey.

Eckel, C.C. \& Grossman, P.J. (2008). Forecasting risk attitudes: An experimental study using actual and forecast gamble choices. Journal of Economic Behavior \& Organization, $68(1), 1-17$.

Eckel, C. C. \& Wilson, R. K. (2004). Is trust a risky decision? Journal of Economic Behavior and Organization, 55, 447-465.

Hanushek, E. (1992). The trade-off between child quantity and quality. Journal of Political Economy, 100(1), 84-117.

Hanushek, E. (2002). Teacher quality. In L.T. Izumi and W.M. Evers (Eds.), Teacher quality (pp. 1-12). Stanford, CA: Hoover Press.

Harbaugh, W.T., Krause, K., \& Vesterlund, L. (2002). Risk attitudes of children and adults: Choices over small and large probability gains and losses. Experimental Economics, 5(1), 53-84.

Harrison, G. W., Johnson, E., McInnes, M. M., and Rutstrom, E. E. (2005). Temporal stability of estimates of risk aversion. Applied Financial Economics Letters, 1(1), 31-35.

Hartog, J., Ferrer-i-Carbonell, A., \& Jonker, N. (2002). Linking measured risk aversion to individual characteristics. Kyklos, 55, 3-26.

Holt, C. A. \& Laury, S. K. (2002). Risk aversion and incentive effects. American Economic Review, 92(5), 1644-1655. 
Howell, W. G., West, M. R., \& Peterson, P. E. (2011). The public weighs in on school reform. Education Next, 11(4), 10-22.

Koedel, C. (2009). An empirical analysis of teacher spillover effects in secondary school. Economics of Education Review, 28(6), 682-692.

Lazear, E. P. (2000). Performance pay and productivity. The American Economic Review, 90, $1346-1361$.

Masclet, D., Colombier, N., Denant-Boemont, L., \& Loheac. Y. (2009). Group and individual risk preferences: A lottery-choice experiment with self-employed and salaried workers. Journal of Economic Behavior \& Organization, 70, 470-84.

Milanowski, A. (2007). Performance pay system preferences of students preparing to be teachers. Education Finance and Policy, 2(2), 111-132.

Moore, E. \& Eckel, C.C. (2003). Measuring ambiguity aversion. Unpublished manuscript, Department of Economics, Virginia Polytechnic Institute and State University.

Perez, M. (2011). Inequity aversion differences: Experimental evidence among prospective teachers and lawyers. Available at SSRN 2018697.

Podgursky, M. (2003). Fringe benefits: There is more to compensation than a teacher's salary. Education Next, 3(3), 71-76.

Prostik, J. (1996). History of teacher pay and incentive reforms. Journal of School Leadership, 6(3), 265-89.

Ritter, G. W. \& Jensen, N. C. (2010). The delicate task of developing an attractive merit pay plan for teachers. Phi Delta Kappan, 37, 32-37. 
Schubert, R., Gysler, M., Brown, M., \& Brachinger, H.W. (1999). Financial decision-making: Are women really more risk averse? American Economic Review Papers and Proceedings, 89, 381-385.

Wagner, T. (2001). Leadership for learning: An action theory of school change. Phi Delta Kappan, 82, 378-83.

Wilms, W. W. \& Chapleau, R. R. (1999, November 3). The illusion of paying teachers for student performance. Education Week. Retrieved from http://www.edweek.org/ew/articles/1999/11/03/10wilms.h19.html. 
Table 1: Lottery Choices

\begin{tabular}{|c|c|c|c|c|c|}
\hline \multirow{2}{*}{ Lottery } & \multicolumn{2}{|c|}{ Option A } & \multirow{2}{*}{$\begin{array}{c}\text { Possible Roll(s) for } \\
\text { Payout }\end{array}$} & \multicolumn{2}{|c|}{ Option B } \\
\hline & $\square$ & Payout & & Payout & $\nabla$ \\
\hline \multirow{2}{*}{1.} & & $\$ 6.00$ & 1 & $\$ 11.55$ & \\
\hline & & $\$ 4.80$ & $2,3,4,5,6,7,8,9,10$ & $\$ 0.30$ & \\
\hline \multirow{2}{*}{2.} & & $\$ 6.00$ & 1,2 & $\$ 11.55$ & \\
\hline & & $\$ 4.80$ & $3,4,5,6,7,8,9,10$ & $\$ 0.30$ & \\
\hline \multirow{2}{*}{3.} & & $\$ 6.00$ & $1,2,3$ & $\$ 11.55$ & \\
\hline & & $\$ 4.80$ & $4,5,6,7,8,9,10$ & $\$ 0.30$ & \\
\hline \multirow{2}{*}{4.} & & $\$ 6.00$ & $1,2,3,4$ & $\$ 11.55$ & \\
\hline & & $\$ 4.80$ & $5,6,7,8,9,10$ & $\$ 0.30$ & \\
\hline \multirow{2}{*}{5.} & & $\$ 6.00$ & $1,2,3,4,5$ & $\$ 11.55$ & \\
\hline & & $\$ 4.80$ & $6,7,8,9,10$ & $\$ 0.30$ & \\
\hline \multirow{2}{*}{6.} & & $\$ 6.00$ & $1,2,3,4,5,6$ & $\$ 11.55$ & \\
\hline & & $\$ 4.80$ & $7,8,9,10$ & $\$ 0.30$ & \\
\hline \multirow{2}{*}{7.} & & $\$ 6.00$ & $1,2,3,4,5,6,7$ & $\$ 11.55$ & \\
\hline & & $\$ 4.80$ & $8,9,10$ & $\$ 0.30$ & \\
\hline \multirow{2}{*}{8.} & & $\$ 6.00$ & $1,2,3,4,5,6,7,8$ & $\$ 11.55$ & \\
\hline & & $\$ 4.80$ & 9,10 & $\$ 0.30$ & \\
\hline \multirow{2}{*}{9.} & & $\$ 6.00$ & $1,2,3,4,5,6,7,8,9$ & $\$ 11.55$ & \\
\hline & & $\$ 4.80$ & 10 & $\$ 0.30$ & \\
\hline \multirow{2}{*}{10.} & & $\$ 6.00$ & $1,2,3,4,5,6,7,8,9,10$ & $\$ 11.55$ & \\
\hline & & $\$ 4.80$ & --- & $\$ 0.30$ & \\
\hline
\end{tabular}


Table 2: Descriptive Statistics

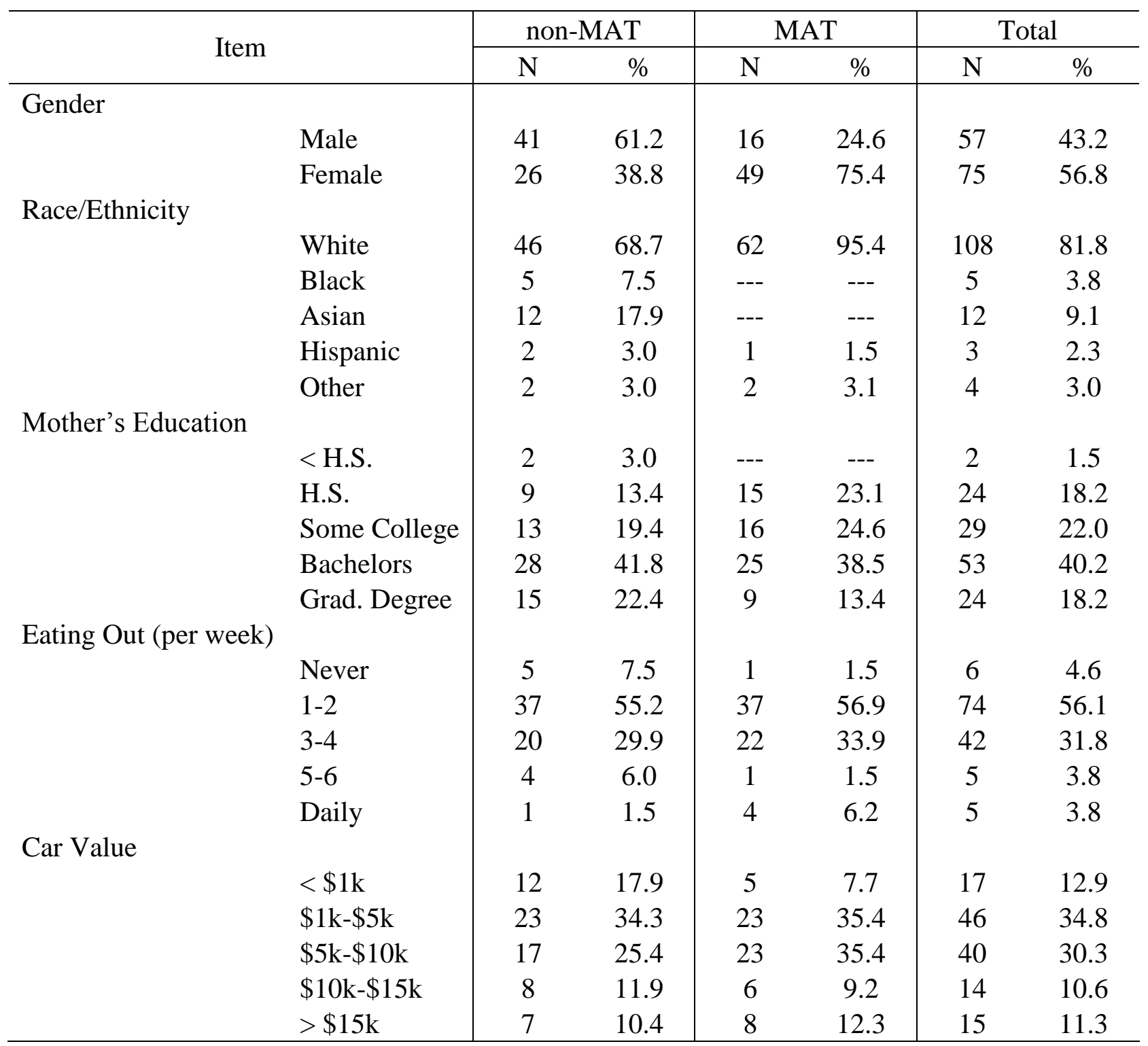

Note: We test for gender and race/ethnicity differences using a chi-squared test. Participants in the MAT group are significantly more likely to be female and white (p-values < 0.01 ). Using a Mann-Whitney two-sample rank-sum test for both mother's education and number of times eating out and a t-test for car values, we find no statistically significant differences between the MAT and non-MAT groups on these items. 
Table 3: Percentages of Confusion with the Risk Elicitation Tool

\begin{tabular}{lccc}
\hline \multicolumn{1}{c}{ Cohort } & $\begin{array}{c}\text { Correct Comprehension } \\
\text { Question }\end{array}$ & Consistent Responses & $\begin{array}{c}\text { Correct and } \\
\text { Consistent }\end{array}$ \\
\hline MBA & $76.7 \%$ & $88.4 \%$ & $74.4 \%$ \\
Law & $91.7 \%$ & $100 \%$ & $91.7 \%$ \\
Elementary MAT & $76.2 \%$ & $85.7 \%$ & $71.4 \%$ \\
Secondary MAT & $81.4 \%$ & $90.9 \%$ & $76.7 \%$ \\
\hline Non-MAT & $82.1 \%$ & $92.5 \%$ & $80.6 \%$ \\
MAT & $76.7 \%$ & $89.2 \%$ & $75.0 \%$ \\
\hline
\end{tabular}


Table 4: Average Number of Safe Choices by Category

\begin{tabular}{|c|c|c|c|c|c|c|}
\hline \multirow{3}{*}{ Degree Type } & \multirow{2}{*}{\multicolumn{2}{|c|}{ All }} & \multicolumn{4}{|c|}{ Gender } \\
\hline & & & \multicolumn{2}{|c|}{ Male } & \multicolumn{2}{|c|}{ Female } \\
\hline & $\mathrm{N}$ & Average & $\mathrm{N}$ & Average & $\mathrm{N}$ & Average \\
\hline non-MAT & 67 & $\begin{array}{c}4.3 \\
(1.4)\end{array}$ & 41 & $\begin{array}{c}4.3 \\
(1.6)\end{array}$ & 26 & $\begin{array}{c}4.3 \\
(1.3)\end{array}$ \\
\hline MAT & 65 & $\begin{array}{c}5.0 \\
(1.9)\end{array}$ & 16 & $\begin{array}{c}5.4 \\
(2.1)\end{array}$ & 49 & $\begin{array}{c}4.9 \\
(1.8)\end{array}$ \\
\hline
\end{tabular}

Note: Standard errors in parentheses. 
Table 5: Statistical Comparison between Subgroups

\begin{tabular}{lcc}
\hline & non-MAT Males & MAT Females \\
MAT Males & $0.018, \mathrm{M}-\mathrm{W}$ & $0.095, \mathrm{M}-\mathrm{W}$ \\
& $0.024, \mathrm{~K}-\mathrm{S}$ & $0.022, \mathrm{~K}-\mathrm{S}$ \\
\hline \multirow{2}{*}{ non-MAT Females } & $0.774, \mathrm{M}-\mathrm{W}$ & $0.122, \mathrm{M}-\mathrm{W}$ \\
& $>0.999, \mathrm{~K}-\mathrm{S}$ & $0.257, \mathrm{~K}-\mathrm{S}$
\end{tabular}

Note: Reported values are estimated p-values for the Mann-Whitney (M-W) and Kolmogorov-Smirnov (K-S) tests for differences in distributions. 
Table 6: Regression Results for Number of Safe Choices

\begin{tabular}{lcccc}
\hline Explanatory Variable & Model 1 & Model 2 & Model 3 & Model 4 \\
\hline \multirow{2}{*}{ MAT } & $0.70^{* *}$ & $0.77^{* *}$ & $1.03^{* *}$ & Positive \& Significant \\
& $(0.29)$ & $(0.32)$ & $(0.51)$ & Not Significant \\
Female & & -0.19 & -0.01 & Not Significant \\
Female*MAT Degree & $(0.32)$ & $(0.43)$ & Not Significant \\
Minority & & -0.27 & Not Significant \\
Age & & $(0.66)$ & \\
Confusion & & $(0.47)$ & Not Significant \\
Constant & & & $(0.02)$ & Positive \& Significant
\end{tabular}

Wealth Proxy 1

Log Car Value

Wealth Proxy 2

Never Eat Out

Eat Out 1-2 times

Eat Out 5-6 times

Eat Out Daily

Wealth Proxy 3

Mother's Education:

Less Than High School

Some College

$-0.18$

(0.48)

Bachelor's

Graduate Degree

$\mathrm{N}$

132

132

132

132

R-Squared

0.04

0.05

0.07

---

Note: Estimates shown for Model 4 are calculated when that is the only wealth proxy included with the explanatory variables present in Model 3. The inclusion of any of the wealth proxies does not qualitatively change the impact of the other explanatory variables (those included in Model 3). Numbers in parentheses below coefficient estimates are standard errors. $* *$ and $* * *$ indicate significance at the $5 \%$, and $1 \% \mathrm{p}$-value levels, respectively, in a two-sided alternative to the null that the coefficient value is 0 . Omitted variables for wealth proxies 2 and 3 are "eat out 3-4 times a week" and "high school" for mother's education, respectively. 
Table 7: Average Ratings for Pay Systems

\begin{tabular}{lccc|ccc} 
Scenario & \multicolumn{3}{c}{ MAT Students } & \multicolumn{3}{c}{ non-MAT Students } \\
& Females & Males & All & Females & Males & All \\
\hline $\begin{array}{l}\text { Pay for individual } \\
\text { performance }\end{array}$ & 2.78 & 2.69 & 2.75 & 2.44 & 3.17 & 2.89 \\
$\begin{array}{l}\text { Pay for developing } \\
\text { your knowledge }\end{array}$ & $(1.65)$ & $(1.54)$ & $(1.61)$ & $(1.87)$ & $(0.97)$ & $(1.42)$ \\
$\begin{array}{l}\text { and skills } \\
\text { Pay for team }\end{array}$ & $(1.39)$ & $(1.75)$ & $(1.48)$ & $(1.36)$ & $(1.80)$ & $(1.64)$ \\
performance & -0.06 & -1.13 & -0.32 & 0.68 & 1.34 & 1.09 \\
$\begin{array}{l}\text { Pay not based on } \\
\text { performance }\end{array}$ & $(2.59)$ & $(2.42)$ & $(2.57)$ & $(2.56)$ & $(2.09)$ & $(2.29)$ \\
& 0.18 & -0.94 & -0.09 & -0.48 & -0.49 & -0.48 \\
\end{tabular}

Note: Standard deviations in parentheses 
Figure 1: Percentage of Safe Choices in Each Lottery by Degree Program

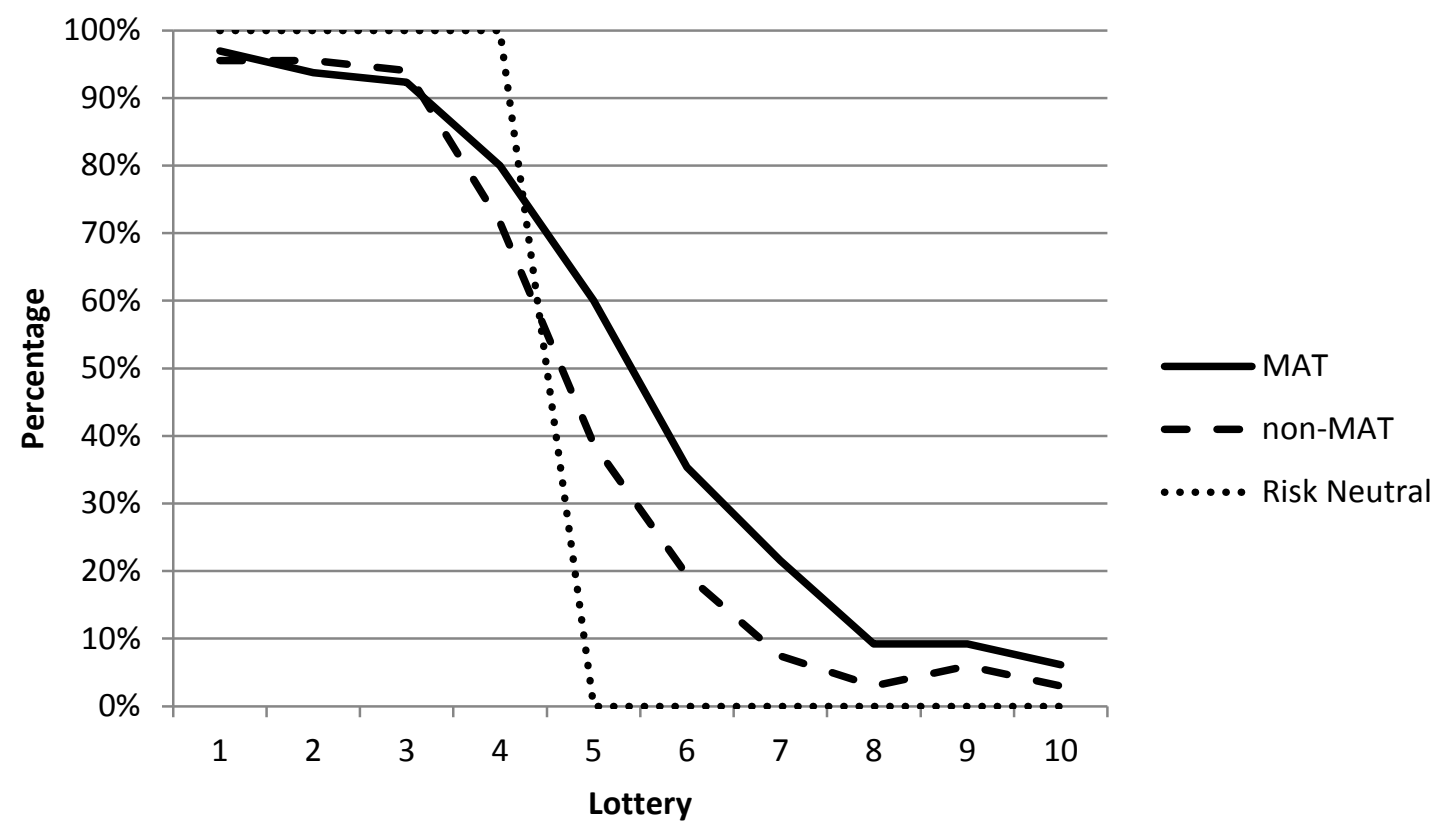


Figure 2: Percentage of Safe Choices in Each Lottery by Gender

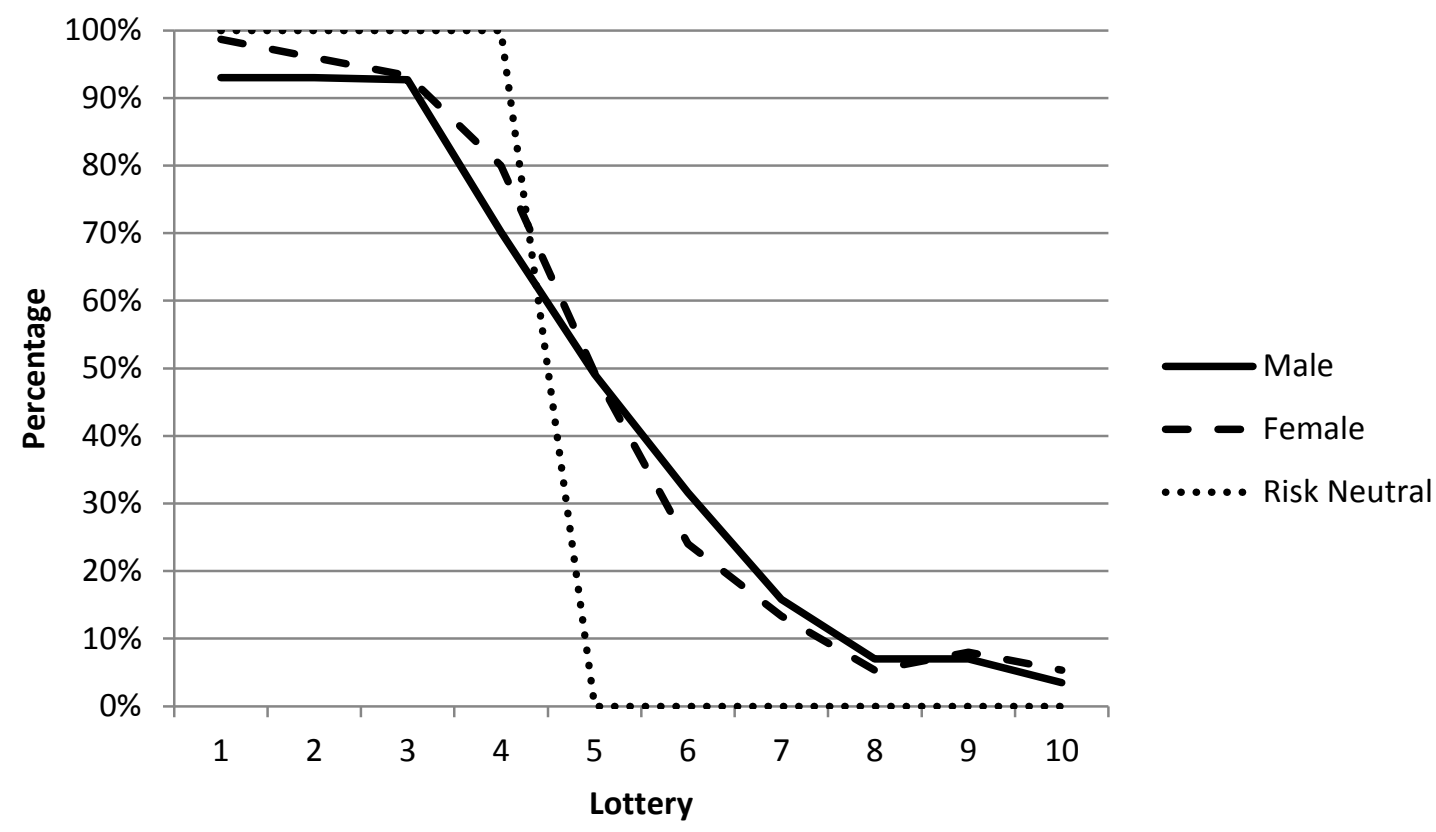


Figure 3: Percentage of Safe Choices in Each Lottery by Degree Program and Sex

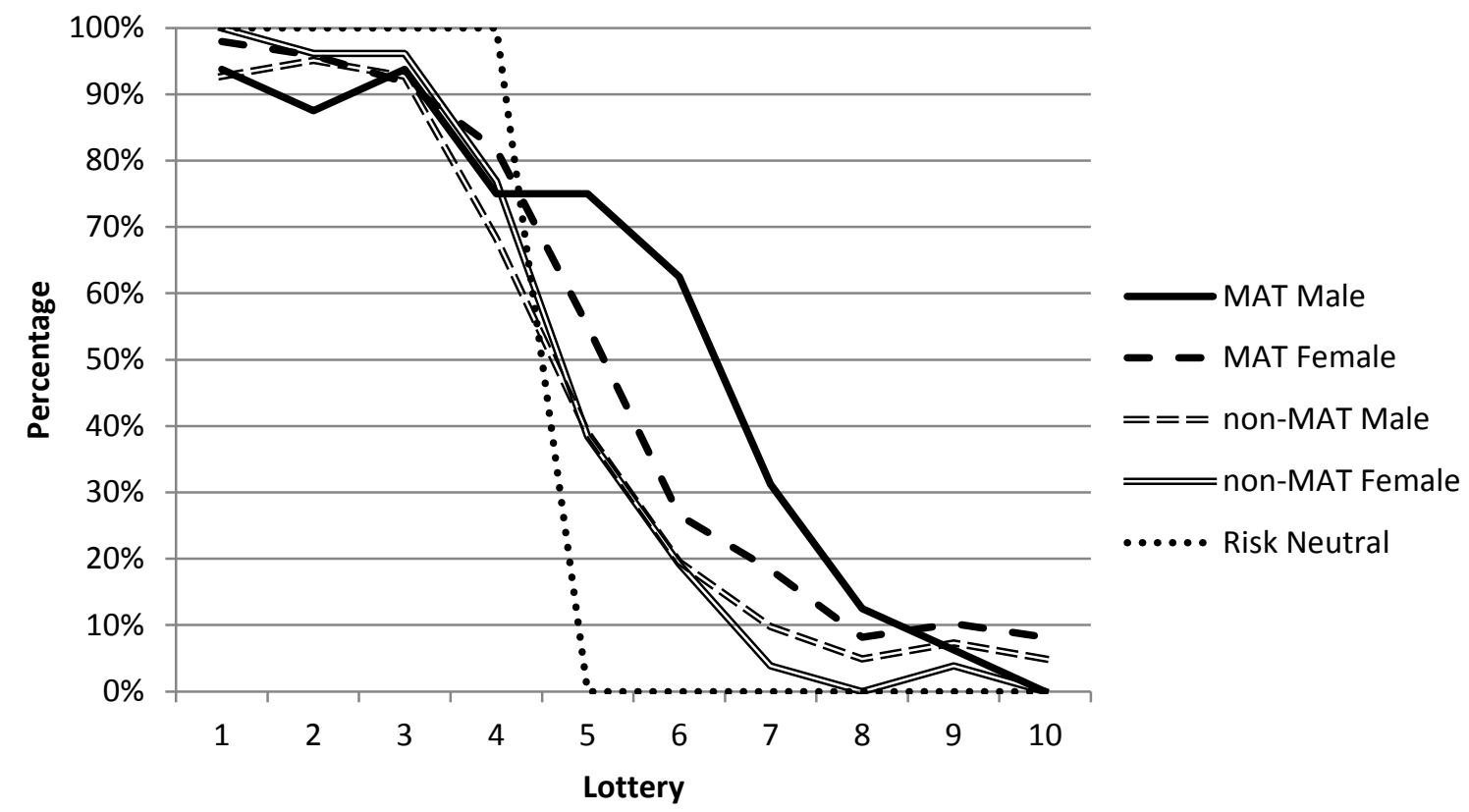




\section{Appendix}

Please complete this page first, then proceed to the back to complete the study. Upon completion you will be paid in cash for your participation as described below.

- For each of the 10 lottery pairs listed below, please indicate if you would prefer Option A or Option B by inserting a check mark in the $\square$ column. Please select only 1 option, either A or B, for each lottery.

- In each lottery pair you will be selecting between a lottery that will pay either $\$ 6.00$ or $\$ 4.80$ (Option A) and a lottery that will pay either $\$ 11.55$ or $\$ 0.30$ (Option B). In the first lottery there is a $10 \%$ chance of receiving the larger payout for lottery 1 and a $90 \%$ chance of receiving the smaller amount. In each subsequent lottery pair the chance of earning the higher payout increases by $10 \%$.

- After you complete this study the experimenter will roll a 10-sided die to randomly select which lottery will be used.

- Next, the experimenter will roll the same die a second time to determine your actual payoff based on the option you chose for that particular lottery.

- The number on the die for the second roll will determine whether you receive Payout 1 or Payout 2.

- Example: If the experimenter's first roll is "3," then your payoff will based on Lottery 3. If you chose Option B for Lottery 3 and the second roll is "1", "2", or " 3 ", you will receive a Payout of $\$ 11.55$, but if the second roll is "4", “5”, “6", "7", “8”, “9” or "10", you will receive a Payout of $\$ 0.30$.

- Please answer the following question which will not impact your payoff but is intended to ensure you understand this task. Suppose the experimenter rolls a "2" first and then rolls a "9". If you have selected Option A for Lottery 2, what will your payout be?

- Please notify the experimenter when you have answered this question before you continue with the experiment.

Lotteries. For each of the 10 lotteries listed below, please indicate if you would prefer Option A or Option B by inserting a check mark in the $\square$ column. Please select only 1 option per lottery.

\begin{tabular}{|c|c|c|c|c|c|}
\hline \multirow{2}{*}{ Lottery } & \multicolumn{2}{|c|}{ Option A } & \multirow{2}{*}{$\begin{array}{c}\text { Possible Roll(s) for } \\
\text { Payout }\end{array}$} & \multicolumn{2}{|c|}{ Option B } \\
\hline & $\square$ & Payout & & Payout & $\bar{\square}$ \\
\hline \multirow{2}{*}{1.} & & $\$ 6.00$ & 1 & $\$ 11.55$ & \\
\hline & & $\$ 4.80$ & $2,3,4,5,6,7,8,9,10$ & $\$ 0.30$ & \\
\hline \multirow{2}{*}{2.} & & $\$ 6.00$ & 1,2 & $\$ 11.55$ & \\
\hline & & $\$ 4.80$ & $3,4,5,6,7,8,9,10$ & $\$ 0.30$ & \\
\hline \multirow{2}{*}{3.} & & $\$ 6.00$ & $1,2,3$ & $\$ 11.55$ & \\
\hline & & $\$ 4.80$ & $4,5,6,7,8,9,10$ & $\$ 0.30$ & \\
\hline \multirow{2}{*}{4.} & & $\$ 6.00$ & $1,2,3,4$ & $\$ 11.55$ & \\
\hline & & $\$ 4.80$ & $5,6,7,8,9,10$ & $\$ 0.30$ & \\
\hline \multirow{2}{*}{5.} & & $\$ 6.00$ & $1,2,3,4,5$ & $\$ 11.55$ & \\
\hline & & $\$ 4.80$ & $6,7,8,9,10$ & $\$ 0.30$ & \\
\hline \multirow{2}{*}{6.} & & $\$ 6.00$ & $1,2,3,4,5,6$ & $\$ 11.55$ & \\
\hline & & $\$ 4.80$ & $7,8,9,10$ & $\$ 0.30$ & \\
\hline \multirow{2}{*}{7.} & & $\$ 6.00$ & $1,2,3,4,5,6,7$ & $\$ 11.55$ & \\
\hline & & $\$ 4.80$ & $8,9,10$ & $\$ 0.30$ & \\
\hline \multirow{2}{*}{8.} & & $\$ 6.00$ & $1,2,3,4,5,6,7,8$ & $\$ 11.55$ & \\
\hline & & $\$ 4.80$ & 9,10 & $\$ 0.30$ & \\
\hline \multirow{2}{*}{9.} & & $\$ 6.00$ & $1,2,3,4,5,6,7,8,9$ & $\$ 11.55$ & \\
\hline & & $\$ 4.80$ & 10 & $\$ 0.30$ & \\
\hline \multirow{2}{*}{10.} & & $\$ 6.00$ & $1,2,3,4,5,6,7,8,9,10$ & $\$ 11.55$ & \\
\hline & & $\$ 4.80$ & --- & $\$ 0.30$ & \\
\hline
\end{tabular}


Scenarios: Below are descriptions of four different methods of providing pay increases to workers. Please read each description, then circle the number that indicates how desirable or undesirable you would find that pay increase method for your first job in your chosen occupation or career field.

1. Pay for individual performance - In this system, you could get up to a 10 percent pay increase each year, depending on your individual job performance, as measured by objective factors. If your job performance was excellent, you would get a 10 percent increase; if very good, a 6 percent increase; if minimally acceptable, a 3 percent increase; and if poor no increase.

\begin{tabular}{l|l|l|l|l|l|l|l|l|l|} 
Highly Undesirable & -4 & -3 & -2 & -1 & 0 & 1 & 2 & 3 & 4 \\
\hline
\end{tabular}

2. Pay for developing your knowledge and skills - In this system, you could get up to a 10 percent pay increase each year, depending on how well you develop a specified body of knowledge and skills, as judged by your supervisor and a group of more experienced peers. If you developed all of the specified skills to a high level, you would receive a 10 percent pay increase. If you developed all of the skills to a satisfactory level, you would receive a 6 percent increase. If you developed some but not all of the skills, you would receive a 3 percent increase. If you did not develop any of the skills, you would get no increase.

\begin{tabular}{l|l|l|l|l|l|l|l|l|l|} 
Highly Undesirable & -4 & -3 & -2 & -1 & 0 & 1 & 2 & 3 & 4 \\
\hline
\end{tabular}

3. Pay for team performance - In this system, you would get up to a 10 percent pay increase each year depending on your team's performance. Performance would be measured by objective factors. If your team's performance was excellent, you would get a 10 percent increase; if very good, a 6 percent increase; if about average, a 3 percent increase; and if poor, no increase.

\begin{tabular}{l|l|l|l|l|l|l|l|l|l|} 
Highly Undesirable & -4 & -3 & -2 & -1 & 0 & 1 & 2 & 3 & 4 \\
\hline
\end{tabular}

4. Pay not based on Performance - In this system, you and all other workers would get a 5 percent pay increase each year regardless of how well or poorly you or your team performed, or how well you developed your skills, as long as you performed well enough to keep your job.

\begin{tabular}{ll|l|l|l|l|l|l|l|l|} 
Highly Undesirable & -4 & -3 & -2 & -1 & 0 & 1 & 2 & 3 & 4 \\
\hline
\end{tabular}

\section{Background Information}
1. Year of Birth:
2. Gender (circle please): Male Female

3. Race/Ethnicity (circle please): White Black Asian Hispanic Other (specify):

4. What graduate degree are you currently working towards? (circle please)

Ed.D. M.A.T. M.B.A M.Ed. Other (specify field and degree):

5. What is your mother's highest level of education? (circle please)

Less than H.S. H. S. Some College Bachelor's Degree Graduate Degree

6. On average, how many times a week do you eat at a restaurant off campus? (circle please)

$$
\text { None 1-2 3-4 5-6 Daily }
$$

7. What is the year, make, and model of your car?

8. What do you think the likelihood is that you go into teaching in a K-12 setting at some point in your life? (circle please)

No Chance (0\%) Very Slim (1-25\%) Modest (26-75\%) Very Likely (76-99\%) Guaranteed (100\%) 